\title{
Techies, thinkers and tinkerers: Why CFHT became a world-class telescope
}

\author{
Liz Bryson \\ Canada-France-Hawaii Telescope \\ 65-1238 Mamalahoa Highway, \\ Kamuela, Hawaii 96743, USA \\ email: bryson@cfht.hawaii.edu
}

\begin{abstract}
Following the celebrated DVD, Gathering the Forgotten Voices, we have embarked on new interviews of the men and women whose hard work and ingenuity forged the technological breakthroughs that maintained CFHT's preeminence as a world-class observatory. While Gathering the Forgotten Voices emphasized the personal history of those involved with the first decade of deep-space observing, the new DVD explores the CFHT innovation in instrumentation from vision through design to construction. It will chronicle the breakthroughs of the observatory's staff so that that record may serve as a prototype for qualitative research at other technological centers.
\end{abstract}

Keywords. Oral history, observatories, telescopes, Mauna Kea, Hawaii

\section{Introduction}

In 2002, while attending the Library and Information Services (LISA IV) conference held at the Charles University in Praque, Czech Republic, I listened to a paper presented by Peter Hingley, Librarian and historian for the Royal Astronomical Society. His paper, entitled The Past in the Present: Some Thoughts on the Preservation of Historical Material in Active Observatories, served as a compelling inspiration for librarians everywhere to plan for the creation and preservation of institutional histories. While I was still mulling over my options as to how to proceed with CFHT's story, in January 2003 a disastrous fire destroyed most of the Mt. Stromlo Observatory including all detailed historical accounts of its long history. It was at that moment, I realized CFHT not only had a tale to tell, but also a unique one at that. This fresh warning spurred my subsequent actions. Ranging across the globe, I collected the life stories of the CFHT creators and implementers. These stories formed the basis of the DVD, Gathering the Forgotten Voices. Fighting against time and distance, we assembled the oral histories of the men and women whose vision resulted in the development and design of a world-class telescope (Bryson 2007).

\section{CFHT Oral History II}

The success of the first DVD caused impetus for considering a second DVD. Whereas the first DVD answered the query: "How did CFHT come to be?"; the second collection of stories attempts to provide answers to the question, "What were CFHT's most famous discoveries?" and "What instruments led the way to our distinction as a first class telescope?" The 1980s were not only years whereby we were getting the telescope up and running, but also the Canadian and French agencies were vested in providing opportunities for promoting their separate instruments; the French, advocating the advancement of its electronic camera and the Canadians giving precedence to the development and use 


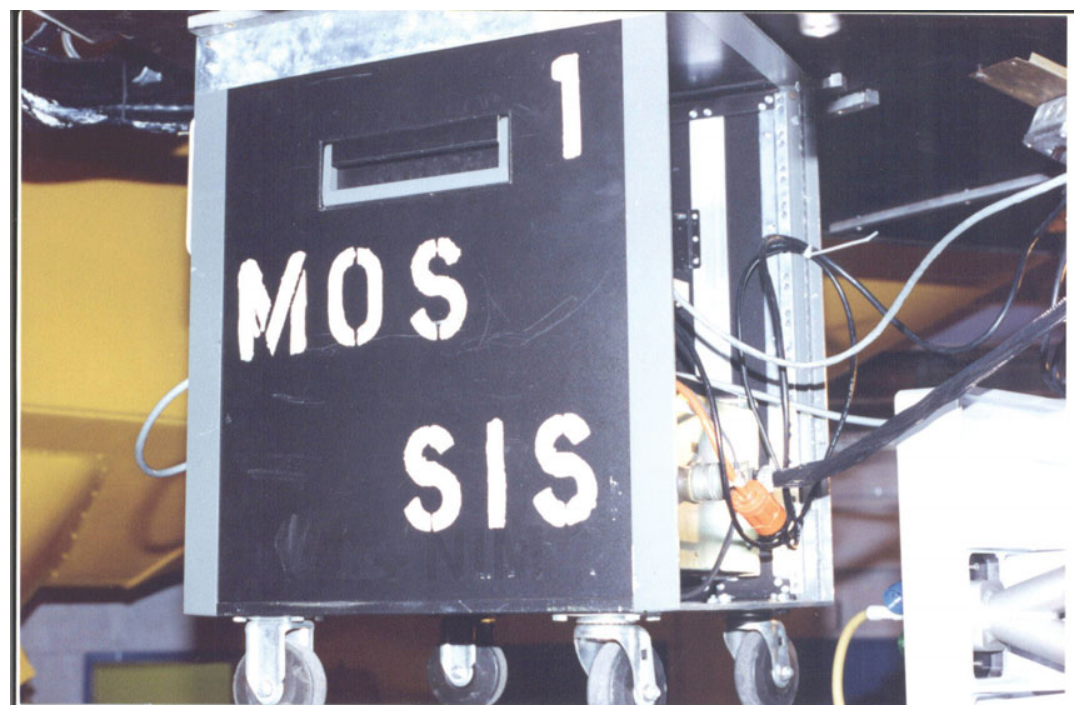

Figure 1. MOS/SIS

of its Herzberg Spectrograph. It became apparent, that if CFHT was to make a scientific impact on astronomy, there needed to be more collaboration between the partners. Not only was the cost of building two separate instruments counterproductive, but it was acknowledged by the CFHT Scientific Advisory Committee (SAC) that only through the sharing of their scientific and technological expertise, could the three countries help the telescope to realize its potential.

Thus, in 1987, Dr. Guy Monnet was appointed Associate Director of CFHT, and with the onset of the 1990s, the CFHT Board of Directors appointed him Executive Director. In my June 2008 interview, Guy reiterated the Board's mandate to him: Find and develop an instrument that would deliver the best images in astronomy. Guy's vision provided the impetus for the creation of two instruments called MOS/SIS; MOS meaning MultiObject Spectrograph) and SIS meaning Subarcsecond Imaging Spectropgraph. According to Guy, the French had already invented the multi-slit concept; hence, it was a natural progression for their scientists to incorporate this technology into seeing; as well, the Canadians were pioneers for the first real-time correction of the atmosphere and the development of the optics. Said Guy, "So, I was responsible for the instrument. I found a group in France, a group in Meudon, essentially to develop the big mechanics and the control for the system, and a group in Canada to develop the optics. It was a challenge to make all these new techniques work and a legacy for the next generation of instruments."

Amazingly, both instruments were completed within four years. MOS was one of the giants of its time, and as a result of team effort, CFHT was a forerunner in building the first large-scale instrument with a very small group of scientists and engineers. We were hailed as pioneers of the multi slit business.

\section{Astronomy comes to the Big Island}

CFHT was an integral part of the astronomy's origins on the Big Island. In 1960, a 9.5 magnitude earthquake occurred off the coast of Chile and nine hours later a tsunami struck Hilo downtown area, devastating and severely impairing an already shaky Big Island economy. In the aftermath of this natural disaster, various schemes, harebrained 


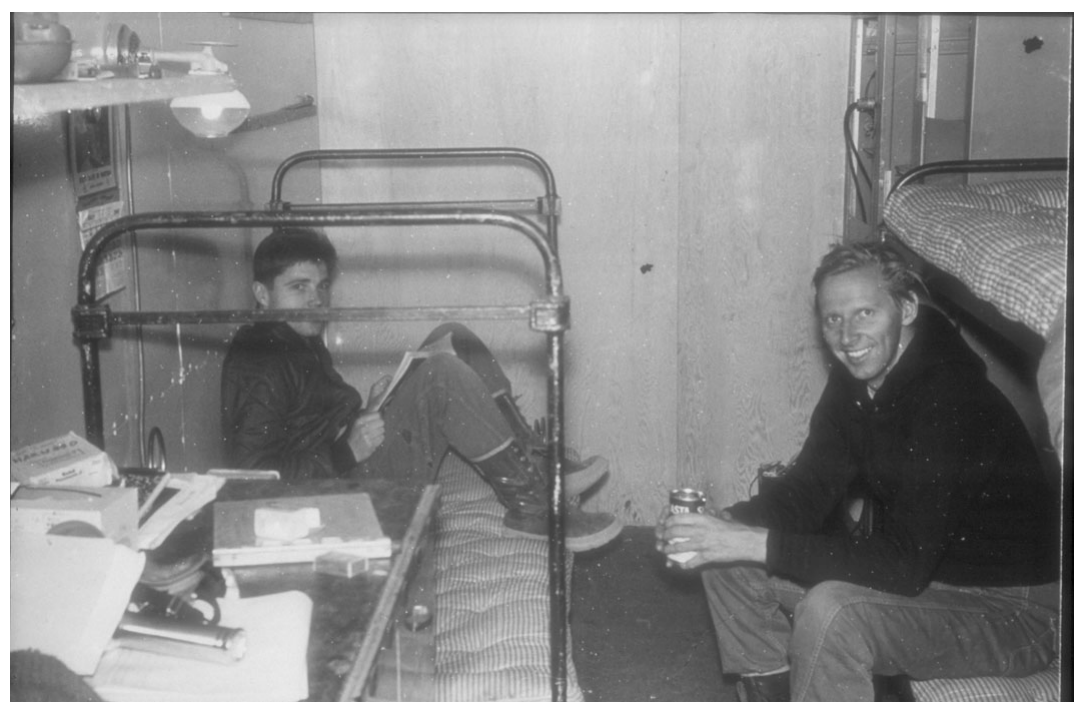

Figure 2. A common man with an uncommon destiny. Jim Harwood (right) taking a break in the van, 1966. (c) J. Hartwood.

and otherwise, were hatched to rejuvenate the local economy, ranging from the marketing of lava to the possibility of developing astronomical facilities. The Chamber of Commerce sent out letters of interest and received only one response from a Dr. Gerard Kuiper, of the Lunar and Planetary Laboratory at the University of Arizona, showing an interest in developing astronomy on Mauna Kea or Maui's Haleakala. By 1964, the Board of Directors of the Hawaii Island Chamber of Commerce approved his recommendation that a portion of Mauna Kea be set aside as a scientific preserve and the first 12.5 inch telescope was dedicated on Mauna Kea. Alika Herring, Kuiper's assistant, made the first observations using his own mirror.

Alika Herring and Dr. Kuiper had done some preliminary site testing on Mauna Kea. At the time, Kuiper was quoted as saying "This mountain is it!...this mountaintop is probably the best site in the world. It is a jewel!"

\section{Jim Harwood: Tinkerer, Institute for Astronomy, 1965-1999}

The dictionary defines "tinkerer" as "a person who tries to fix or mend". According to this definition, Jim Harwood was a "tinkerer". From early on, Jim exhibited these attributes that would later help the CFHT Observatory to be built. His inventiveness would help the early constructors of the telescope to overcome several initial conundrums. In 1965, John Jefferies, the newly appointed Director of the Institute for Astronomy (IfA), charged Harwood with completing the road to the summit of Mauna Kea. The harsh conditions for these pioneers of science cannot be understated. For over a year, Jim and two other colleagues lived at an altitude of 10,000 feet in a house trailer on Mauna Kea. Their humble cottage had been salvaged from a missile-tracking station at South Point on the Big Island.

Harwood had to improvise on more than his shelter. Simple cooking was a challenge. On his thirtieth birthday, Harwood, doubling the 5,000 foot altitude adjustment that such a recipe called for, baked brownies for a birthday cake. It seemed simple math. He had to use a hammer and screwdriver to make a hole for the candle. Needless to say, the brownies were inedible. 


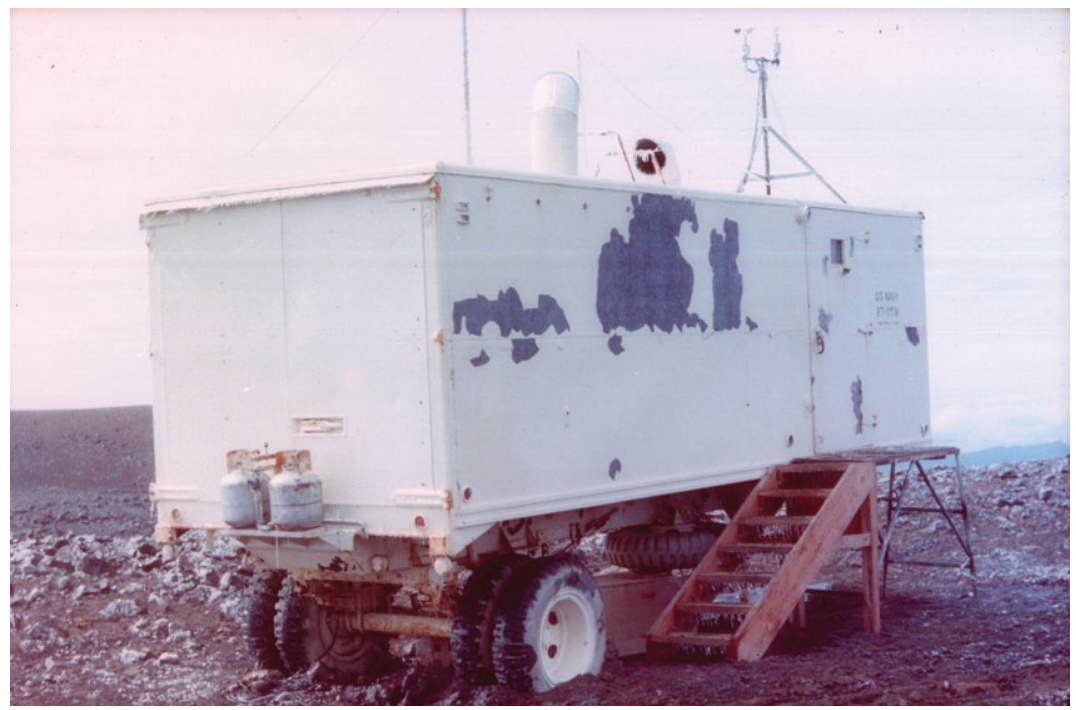

Figure 3. Him's "home", 1966. (c) J. Hartwood.

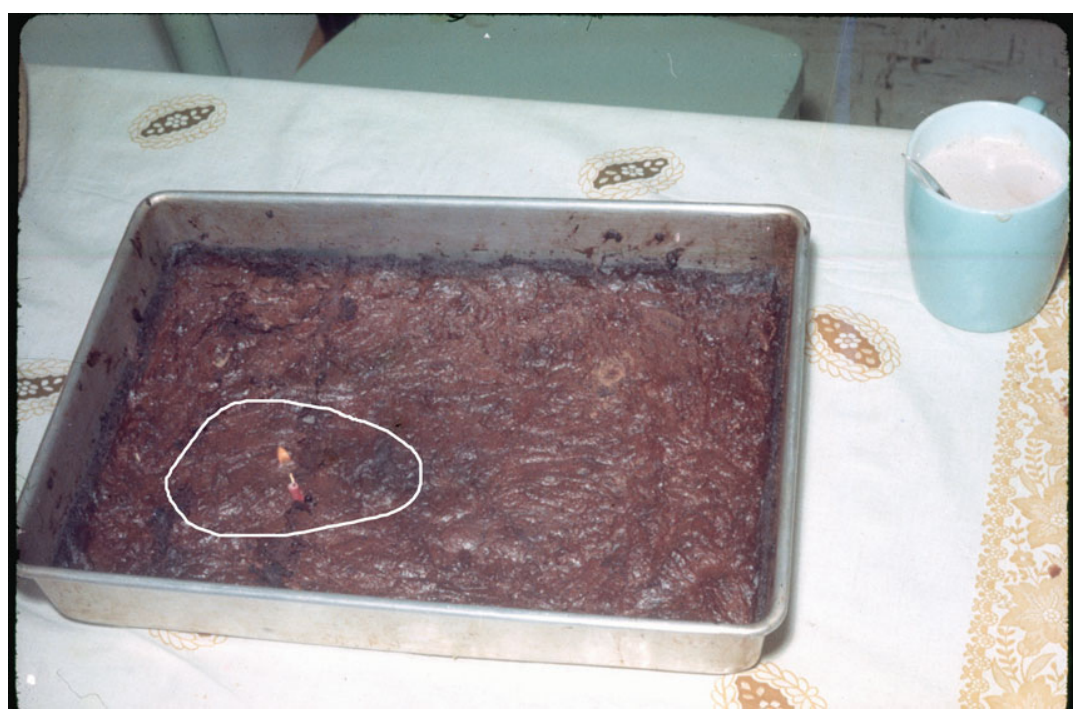

Figure 4. High-altitude brownies, 1966. (c) J. Hartwood.

Building the summit road required more ingenuity than baking birthday brownies, but Harwood and his colleagues persevered.

\section{Dr. Howard Yee: Astronomer and thinker}

"During the 90s MOS carried out three of the largest surveys in the world. There wasn't anything that came close".

A "thinker" is defined as "one who devotes time to thinking or meditation". Howard Yee is a "thinker". Yee is always thinking about his work, and when not thinking about his work, he seeks solace in mountain climbing, a pursuit that requires as much thought as strength. In 1992, a group met in Canada with the hope that upon using MOS they would be able to determine the average mass density of the Universe. The group came 


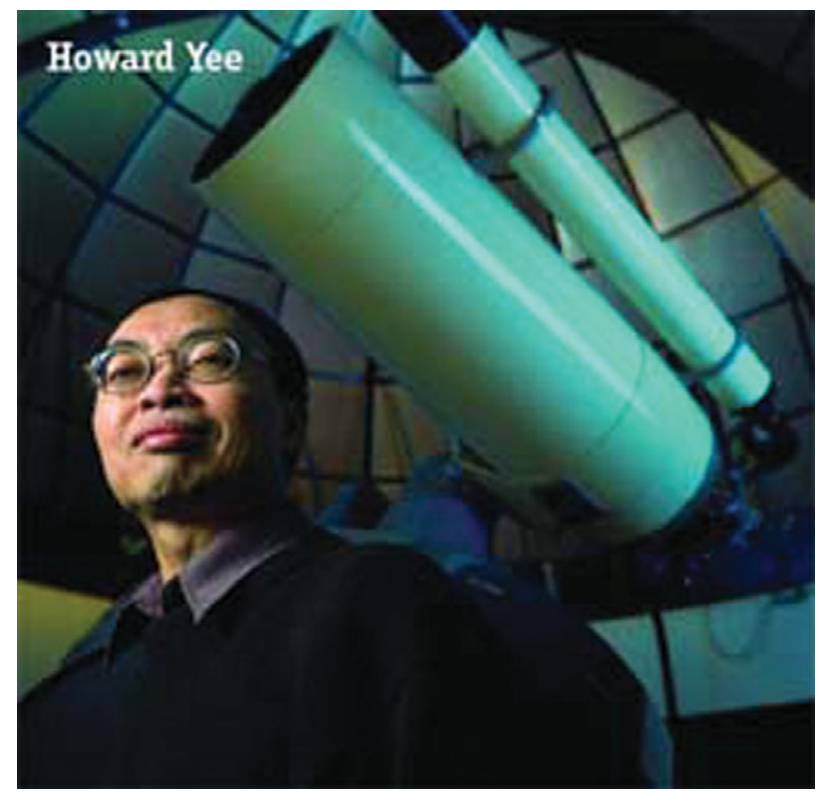

Figure 5. Dr. Howard K.C. Yee.

to be known as CNOC I and CNOC II, an abbreviation for the Canadian Network for Observation of Cosmology.

During our interview, Yee said they were able to acquire twelve nights for observing on MOS in one semester, and that was the single largest allocation, at that time, for a project. Initially, they knew that galaxies changed with time as stars were born and died; but, more significantly, as a result of their observations, they were able to acquire a big enough sample of several thousand galaxies out to a distance of seven billion light years; thus, looking back to see their properties. This backward look discovered that many galaxies were brighter in the past and some were bluer, and, with these observations, CNOC was able to quantify this change in these, never-before-seen galaxies.

\section{Dr. Olivier Lai: Astronomer and techie}

"The credit to CFHT is that it took risks. They decided to not do the traditional Shack-Hartmann system although there was such a fear that the curvature systems might not work, there is a whole quarter of Adaptive Optics Bonnette inside which is empty, with room for another wave-front sensor of the Shack-Hartman type, ... just in case."

Another measure of collaboration was the development of an adaptive optics bonnette project or, PUEO, the name of a Hawaiian owl. The implication was, that like the AO system, it is a night bird and has sharp vision. The Adaptive Optics system was developed at the IfA (Institute for Astronomy), UH-Manoa with assistance in design from Canada, France and the CFHT staff. It was ready for use in 1996 and the images were immediately seen as crisper in detail. Here is another example in which CFHT was a key test-bed for many of the early developments in this field.

Dr. Olivier Lai, who oftentimes has five computers working simultaneously, is a "techie" or "one who studies or is highly proficient in the technical field". In 1993, Lai met Dr. Daniel Rouan, who persuaded Olivier that AO was currently a hot topic and invited him 


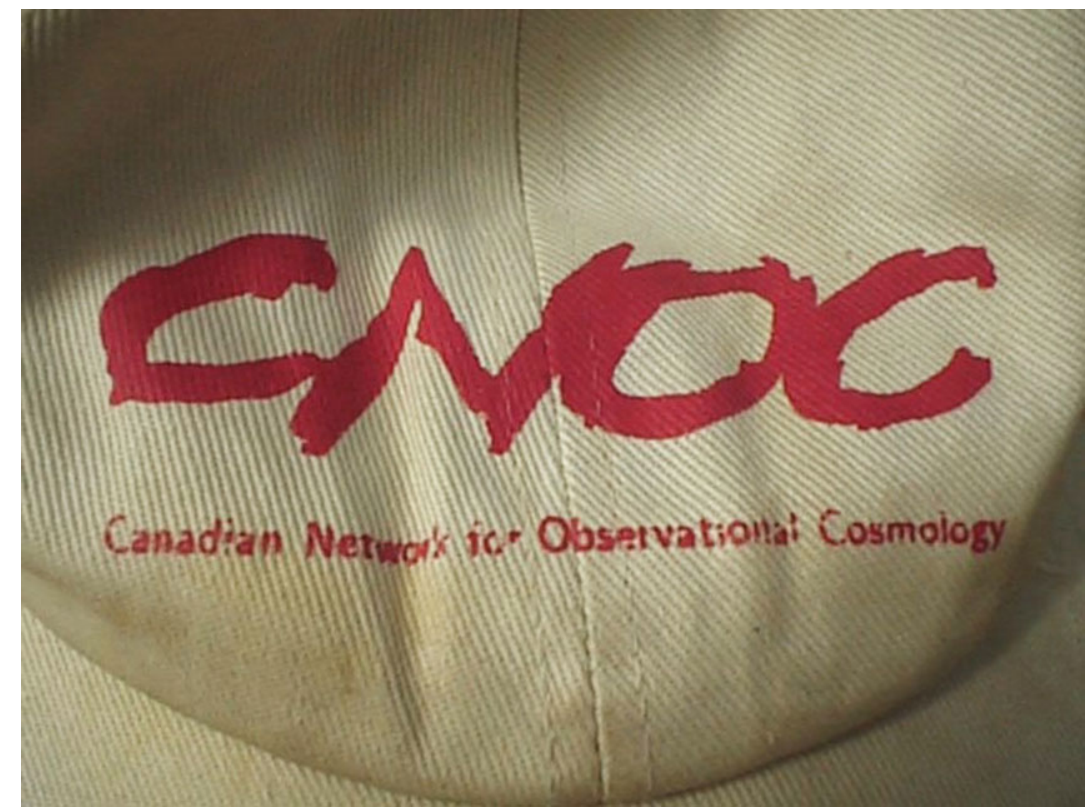

Figure 6. Canadian Network for Observational Cosmology.

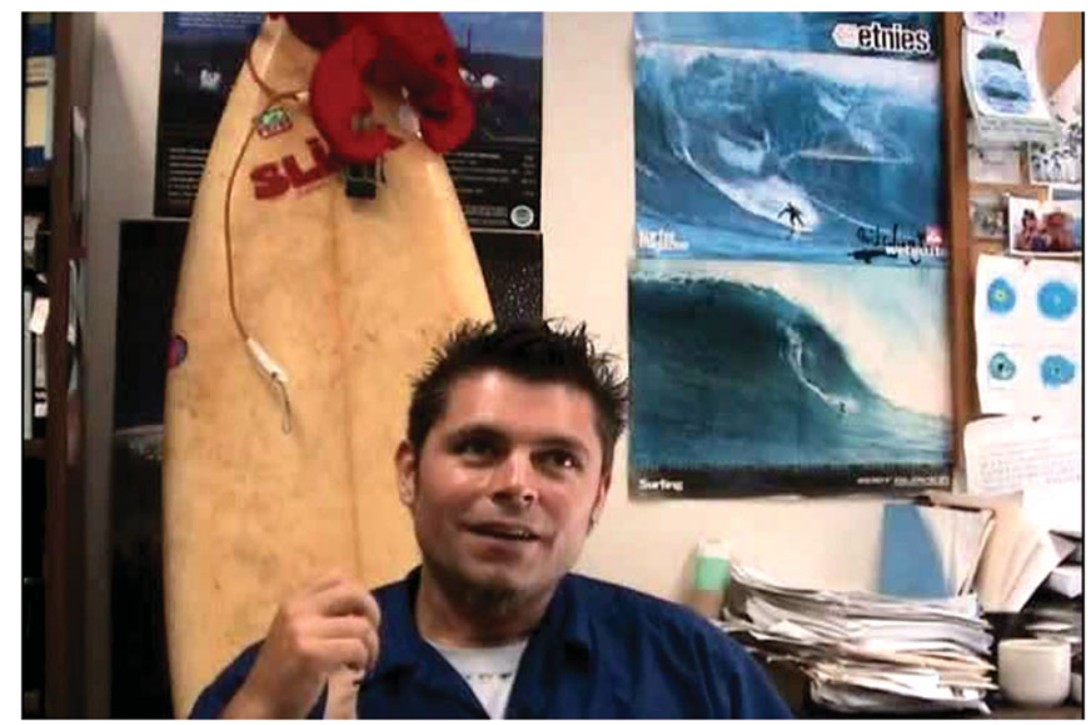

Figure 7. Dr. Olivier Lai, CFHT.

to participate in the integration and testing of CFHT's AO system at a laboratory in Meudon, France.

All oral history is subjective. In fact, subjectivity is its strength. Nowhere is this more evident than in Olivier's discourse on the evolution of adaptive optics; in fact, he breathed new life into what could have been a drab discourse on the subject as follows:

"Debate regarding adaptive optics still goes on to this day. The one camp, or school, advocates using really military technology. It is easy to understand how 
it works, easy to grasp, but not well suited to astronomical application; the astronomer Dr. François Roddier, thought this type of application was wasteful because astronomers looked for objects that are faint and most likely in the infrared; therefore, Roddier developed a system that took into account the specifics of astronomy. However, for reasons yet to be understood, there has been a huge amount of social resistance to accepting this technology."

Olivier is uncertain as to the rationale for this, other than, "Conceptually it's just more difficult to understand".

\section{Techies, thinkers and tinkerers lead the way}

In 1965, Jim Harwood and two colleagues prepared the road to Mauna Kea and a new era began in astronomy. By 1970, CFHT was one of the first observatories to step out fully into the international community and by the mid 90s, CFHT had become a model for scientific innovation and multi-national collaboration. It is only fitting that in the International Year of Astronomy, CFHT celebrates its Thirtieth anniversary as our techies, thinkers and tinkerers continue in their pursuit of keeping CFHT at the forefront of scientific excellence.

The CFHT oral history project is committed to capture its distinct history, both now and in the future.

\section{Reference}

Bryson, L. 2007, in Library and Information Services in Astronomy V, S. Ricketts, C. Birdie and E. Isaksson (eds), ASP Conference Series, Vol. 377 (San Francisco: Astronomical Society of the Pacific), p. 350 